Research article

\title{
Chromogenic in situ hybridisation for the assessment of HER2 status in breast cancer: an international validation ring study
}

\author{
Marc van de Vijver ${ }^{1}$, Michael Bilous ${ }^{2}$, Wedad Hanna ${ }^{3}$, Manfred Hofmann ${ }^{4}$, Petra Kristel ${ }^{1}$, \\ Frédérique Penault-Llorca ${ }^{5}$ and Josef Rüschoff ${ }^{4}$
}

\author{
${ }^{1}$ Netherlands Cancer Institute, Amsterdam, The Netherlands \\ 2Westmead Hospital, Westmead, New South Wales, Australia \\ ${ }^{3}$ Sunnybrook \& Women's College, Health Science Center, Toronto, Canada \\ ${ }^{4}$ Klinikum Kassel, Kassel, Germany \\ ${ }^{5}$ Departement de Pathology, Centre Jean Perrin, Clermont-Ferrand, France \\ Corresponding author: Marc van de Vijver, m.vd.vijver@nki.nl
}

Received: 26 Jun 2006 Revisions requested: 5 Sep 2006 Revisions received: 12 Jun 2007 Accepted: 8 Oct 2007 Published: 8 Oct 2007

Breast Cancer Research 2007, 9:R68 (doi:10.1186/bcr1776)

This article is online at: http://breast-cancer-research.com/content/9/5/R68

(C) 2007 van de Vijver et al.; licensee BioMed Central Ltd.

This is an open access article distributed under the terms of the Creative Commons Attribution License (http://creativecommons.org/licenses/by/2.0), which permits unrestricted use, distribution, and reproduction in any medium, provided the original work is properly cited.

\begin{abstract}
Introduction Before any new methodology can be introduced into the routine diagnostic setting it must be technically validated against the established standards. To this end, a ring study involving five international pathology laboratories was initiated to validate chromogenic in situ hybridisation (CISH) against fluorescence in situ hybridisation (FISH) and immunohistochemistry (IHC) as a test for assessing human epidermal growth factor receptor 2 (HER2) status in breast cancer.
\end{abstract}

Methods Each laboratory performed CISH, FISH and IHC on its own samples. Unstained sections from each case were also sent to another participating laboratory for blinded retesting by CISH ('outside CISH').

Results A total of 211 invasive breast carcinoma cases were tested. In 76 cases with high amplification (HER2/CEP17 ratio $>4.0$ ) by FISH, 73 cases (96\%) scored positive (scores $\geq 6$ ) by 'outside CISH'. For FISH-negative cases (HER2/CEP17 ratio
$<2.0$ ), 94 of 100 cases $(94 \%)$ had CISH scores indicating no amplification (score $\leq 5$ ), and only three cases were positive by $\mathrm{CISH}$; in the three remaining cases, no $\mathrm{CISH}$ result could be obtained. For cases with low-level amplification using FISH (HER2/CEP17 ratio 2.0-4.0), 20 of 35 had CISH scores indicating gene amplification. Inter-laboratory concordance was also very high: $95 \%$ for normal HER2 copy number (1-5 copies); and $92 \%$ for cases with HER2 copy numbers $\geq 6$. $\mathrm{CISH}$ intra-laboratory concordance with $\mathrm{IHC}$ was $92 \%$ for $\mathrm{IHC}$ negative cases $(\mathrm{IHC} \mathrm{0/1+)}$ and $91 \%$ for $\mathrm{IHC} 3+$ cases. Among IHC $2+$ cases, $\mathrm{CISH}$ was $100 \%$ concordant with samples showing high amplification by $\mathrm{FISH}$, and $94 \%$ concordant with FISH-negative samples.

Conclusion These results show that $\mathrm{CISH}$ inter- and intralaboratory concordance to FISH and IHC is very high, even in equivocal IHC $2+$ cases. Therefore, we conclude that $\mathrm{CISH}$ is a methodology that is a viable alternative to FISH in the HER2 testing algorithm.

\section{Introduction}

Human epidermal growth factor receptor 2 (HER2) is strongly overexpressed in 20-30\% of human breast cancers (the HER2 gene is also known as ERBB2 or neu). HER2 is a 185 $\mathrm{kDa}$ transmembrane growth factor receptor with tyrosine kinase activity, and has been shown to play a role in the signal transduction of cell growth $[1,2]$. It has been shown in many studies that overexpression of the HER2 protein correlates with amplification of the HER2 gene [3-7]. A HER2-positive status has been associated with a poor prognosis, including aggressive disease and shorter survival [8], and there also is evidence that HER2-positive tumours differ from HER2-negative tumours in their responsiveness to chemotherapy and hormonal therapy [9-14].

Trastuzumab (Herceptin), a humanised monoclonal antibody, has been specifically developed to target HER2. Trastuzumab has been shown unequivocally to confer a survival benefit in 
the treatment of women with HER2-positive breast cancer $[15,16]$. As responsiveness to trastuzumab therapy is directly linked to a patient's HER2 status, accurate determination of HER2 status is essential for identifying patients who may benefit from this form of treatment. It has been clearly shown that HER2-positive patients, that is, patients whose tumours show strong overexpression of HER2 as indicated by an immunohistochemistry (IHC) score of $3+$, and/or whose tumours show HER2 gene amplification as determined by a positive fluorescence in situ hybridisation (FISH) result, derive the greatest therapeutic benefit from treatment with trastuzumab $[15,17]$.

Several different techniques have been used to determine HER2 status in breast cancer specimens, including Southern, northern and western blots, ELISA, and PCR. However, only two technologies for HER2 status determination are currently validated for use in the routine diagnostic setting: $\mathrm{IHC}$, which identifies HER2 protein expression on the cell surface, and $\mathrm{FISH}$, which determines the degree of HER2 gene amplification. Both methods are highly specific and reproducible when performed with a standardised and validated testing protocol.

IHC is far more widely used than FISH. The IHC test for HER2 is semi-quantitative, relating the intensity of the immunostaining to the number of HER2 receptors on the tumour cell's surface. The reagents for the $\mathrm{IHC}$ test for the identification of HER2 are relatively inexpensive, the technique is quick, results can be achieved using a conventional light microscope, and the resulting stained slides are easy to preserve and archive. In addition, IHC allows tumour cell morphology to be evaluated by light microscopy. However, variations in methods can affect the results of IHC staining, leading to equivocal results. Such variations can include sample storage conditions, type of fixative used, duration of fixation and type of antibody used. The scoring system for HER2 staining categorises tumours as 3+ (strongly positive staining), 2+ (moderately strong staining), $1+$ (weak staining) and 0 (negative for staining). An IHC score of $3+$ is classified as positive for HER2 overexpression, but a score of $2+$ by IHC is generally considered equivocal; 0 or $1+$ are considered HER2 negative. FISH identifies the number of copies of the HER2 gene, normally in conjunction with the number of chromosome 17 centromere copies, and is generally seen as being more quantitative than IHC. Furthermore, as DNA is more stable than protein, pre-analytical factors have less impact on test results compared with IHC. However, is more expensive than $\mathrm{IHC}$ and takes longer to perform. It also requires special training and access to a fluorescence microscope, which are not available to many laboratories conducting routine diagnostic screening. In addition, the signals produced by the FISH assay decay within a few weeks.

A HER2 testing algorithm has been proposed, and is recommended in most national and international HER2 testing guidelines [18]. Normally, IHC is performed as the initial test to determine HER2 status. Eligibility is clear if the $\mathrm{IHC}$ score is either $3+$ or $0 / 1+$; women with $\mathrm{IHC} 3+$ tumours are eligible for trastuzumab, whereas those with $\mathrm{IHC} 0 / 1+$ tumours are not. Women whose tumours produce an equivocal score (IHC 2+) should be retested with FISH; a positive score by FISH is required to confirm eligibility for trastuzumab. However, in cases where FISH is used as the initial test, a positive FISH score indicates eligibility for trastuzumab.

Due to the technical difficulties associated with FISH outlined above, alternative methods of assessing HER2 gene amplification status are being investigated. Chromogenic in situ hybridisation $(\mathrm{CISH})$ is similar to $\mathrm{FISH}$ in that it identifies the degree of HER2 gene amplification, and has the same advantages of a DNA-based assay. However, visualisation is achieved using a peroxidase-based chromogenic reaction, similar to IHC. Therefore, unlike FISH, positive signals can be identified using an ordinary light microscope. The signal does not decay, so results can be archived and stored. In recent years, $\mathrm{CISH}$ has been evaluated and compared with the established testing standards, IHC and $\mathrm{FISH}$, in a number of studies [19-23]. Most of these studies reported very high rates of concordance $(>85 \%)$ and thus agreement between these methods. Although it has been shown that when two observers evaluate the same $\mathrm{CISH}$ stained slides, inter-observer variability is low [19], inter-laboratory concordance of $\mathrm{CISH}$ has not been extensively investigated. To this end, we initiated a ring study involving five international pathology laboratories, to technically validate $\mathrm{CISH}$ against the established standard tests for HER2 status and to assess both the intra- and interlaboratory agreement of $\mathrm{CISH}$.

\section{Materials and methods Tumour specimens}

Each laboratory in the ring study provided $40-50$ primary invasive breast carcinoma specimens that had been successfully pre-assessed at the original laboratory for HER2 status by both IHC and FISH. Each laboratory included as many cases with low-level amplification assessed by FISH as possible; such cases are relatively rare, but were considered to be of great interest for comparing results of $\mathrm{FISH}$ and $\mathrm{CISH}$ testing. Each laboratory provided roughly 20 cases scored by FISH as having no amplification, 15 cases scored as achieving highlevel amplification, and 6 cases scored as having low-level amplification. Specimens were formalin-fixed (fixation time ranged from 12-48 hours) and embedded in paraffin blocks. Tissue sections for $\mathrm{CISH}$ analysis were $4-5 \mu \mathrm{m}$, mounted on coated slides.

All specimens were coded for this study; in accordance with the regulations provided by the medical ethical committees from the participating institutes, the data cannot be linked to patient information. 
Figure 1

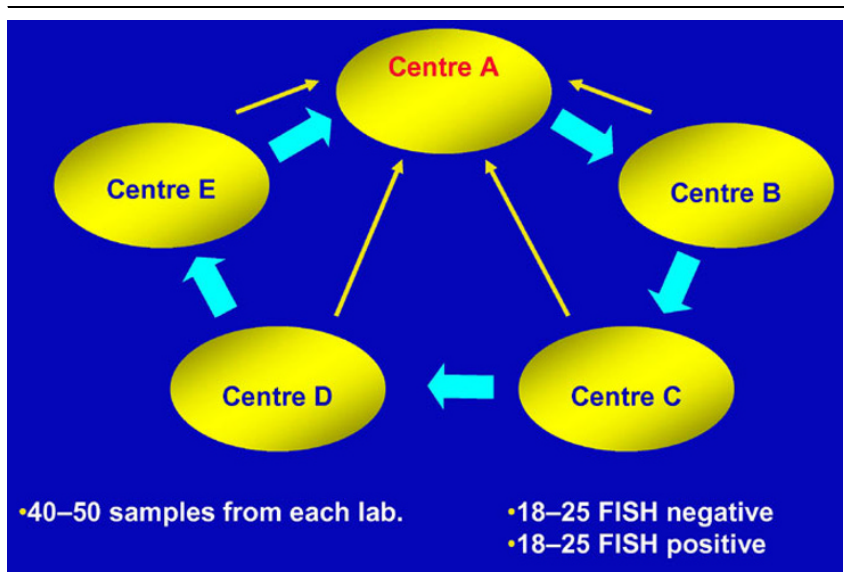

Study design. Each of the 5 centres forward 5 blinded, unstained slides from each sample to the next centre for chromogenic in situ hybridisation $(\mathrm{ClSH})$ analysis (thick arrows). Results from each centre are reported back to centre A every 2 months (thin arrows).

\section{Assays}

The HercepTest (DakoCytomation, Glostrup, Denmark) was used for IHC testing in most of the participating centres; where alternative assays were used, these had been rigorously evaluated using control cases. The results can be considered to be equivalent to those achieved using the HercepTest assay. The PathVysion kit (Vysis, Abbott, Illinois, USA) was used for FISH testing and the SpoT-LIGHT CISH polymer detection kit (Invitrogen, Carlsbad, California, USA) for $\mathrm{CISH}$ testing. All assays were conducted as per the manufacturers' instructions or, where TAB250 and CB-11 staining was used, an internally validated and standardised staining protocol.

\section{Study design}

Five pathology laboratories, each from a different country, participated in the study. Each laboratory conducted IHC, FISH and $\mathrm{CISH}$ ('own $\mathrm{CISH}$ ') on all their samples. Seven to eight slides were prepared for each breast cancer specimen. Five unstained slides from each sample were sent to the next laboratory for $\mathrm{CISH}$ analysis ('outside $\mathrm{CISH}^{\text {; }}$ Figure 1). The laboratory was blinded to the previous $\mathrm{CISH}, \mathrm{FISH}$ or IHC results. All scoring results were sent to one laboratory where the correlation between 'outside' $\mathrm{CISH}$ and own $\mathrm{CISH}, \mathrm{FISH}$ and $\mathrm{IHC}$ results were calculated.

An additional 15 unstained slides, prepared from one representative breast cancer sample (with areas of HER2-amplified tumour cells and normal tissue) were also sent to the next laboratory in the ring study. These slides were used to conduct a pepsin-time course to determine the optimal digestion time for the sample. The optimal pepsin digestion time was then used in the preparation of the slides tested by $\mathrm{CISH}$.

\section{Scoring of results}

Results for all assays were scored according to the manufacturers' instructions. The results of the $\mathrm{IHC}$ tests were scored using the HercepTest scoring system (0-3+). The results of FISH PathVysion kit were scored as follows: a sample was classified as not amplified if it had a HER2/CEP17 ratio of $<2.0$, low amplified if it had a HER2/CEP17 ratio of 2.0-4.0, and high amplified if it had a HER2/CEP17 ratio of $>4.0$.

For $\mathrm{CISH}$, the number of HER2 signals per nucleus was counted (at $400 \times$ magnification) and categorised as $<5$ spots, 5 spots, 6 spots or $>6$ spots (tumours with a large cluster of amplified spots per nucleus were also scored as $>6$ spots). The scoring system was adapted from the protocol information provided by Invitrogen. At least 30 tumour cells from each specimen were analysed if the sample was deemed homogeneous, but at least 60 cells were analysed if the sample was found to contain between 5 and 10 HER2 gene copies in $>50 \%$ of the area selected for evaluation. The proportion of evaluable tumour cells and the ability to detect normal HER2 copy numbers in non-tumour cells were also recorded.

If $\mathrm{CISH}$ staining was not successful, this was indicated as 'no signal'.

\section{Additional quality assessments performed}

Heterogeneous quality of the staining result may occur with $\mathrm{CISH}$. To evaluate the extent of heterogeneity in the study results, the percentage of tumour cells with a good $\mathrm{CISH}$ result was recorded for each case tested.

A significant advantage that $\mathrm{CISH}$ has over $\mathrm{FISH}$ is that histology can be examined using a light microscope. Therefore, it was possible to evaluate the morphology of the tumour cells in this study by standard light microscopy. The morphology was categorised as excellent, good, reasonable or poor.

\section{Results}

A total of 211 cases were scored. Typical $\mathrm{CISH}$ results are shown (Figure 2). Gene copies can be identified as dots in the nuclei of the cells.

\section{Inter-laboratory correlation between FISH and CISH}

The correlation between the results of FISH testing in the sending laboratory and $\mathrm{CISH}$ in the blinded laboratory receiving the unstained slides (outside $\mathrm{CISH}$ ) is summarised in Table 1. Most cases (70 of 76 cases; 92\%) that had a high level of amplification by FISH (HER2/CEP17 ratio of $>4.0$ ), were scored as having high amplification by $\mathrm{CISH}$ (copy number $>6)$. Three cases $(4 \%)$ were scored by $\mathrm{CISH}$ as having a HER2 copy number of 6 , indicating a low level of gene amplification. Three more cases (4\%) were negative for amplification by $\mathrm{CISH}$; two of these cases contained five HER2 gene copies and one contained $<5$ gene copies as determined by $\mathrm{CISH}$. 
Figure 2
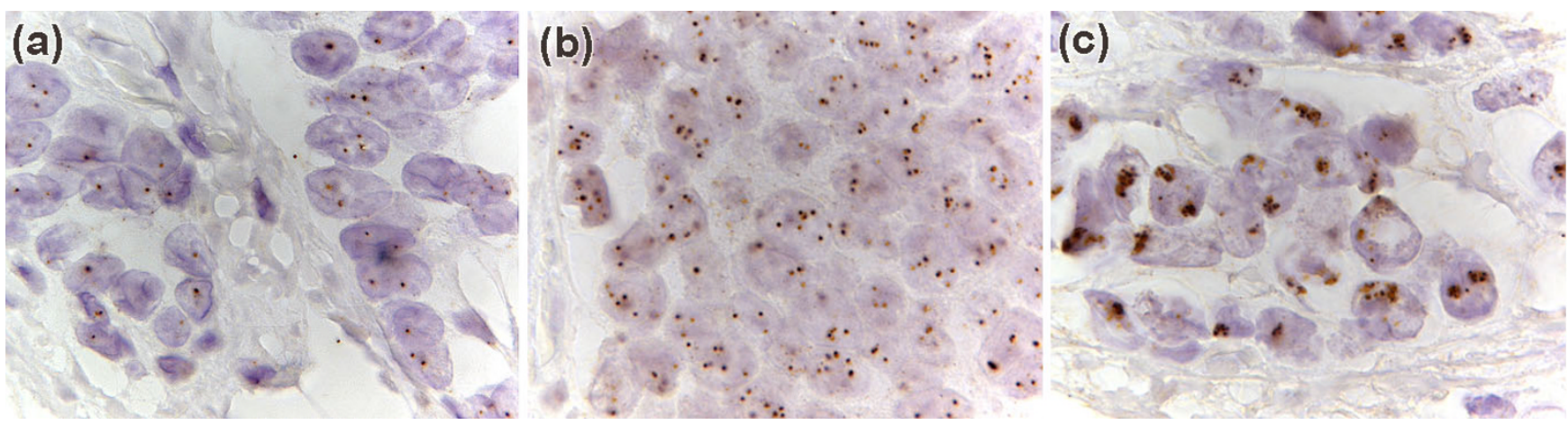

(a) chromogenic in situ hybridisation (CISH) on a breast carcinoma with normal HER2 copy number (1000x). An average of two darkly brown staining copies of the HER2 gene can be seen in each tumour cell. (b) CISH on a breast carcinoma with low level HER2 gene amplification (1000x). An average of 6 copies of the HER2 gene can be seen in each tumour cell. (c) $\mathrm{CISH}$ on a breast carcinoma with high level HER2 gene amplification (1000x). Large clusters of darkly brown staining HER2 copies can be seen in each tumour cell. It is not possible to count the exact number of $H E R 2$ gene copies; this is the usual result seen in tumours with high HER2 gene amplification.

Table 1

Inter-laboratory correlation between FISH and CISH

\begin{tabular}{|c|c|c|c|c|c|c|}
\hline \multirow[b]{2}{*}{ FISH HER2/CEP17 ratio } & \multicolumn{5}{|c|}{$\mathrm{CISH}$ (number of signals) } & \multirow[b]{2}{*}{$n$} \\
\hline & $<5$ & 5 & 6 & $>6$ & No signal & \\
\hline$<2.0$ & 91 & 3 & 0 & 3 & 3 & 100 \\
\hline $2.0-4.0$ & 11 & 4 & 5 & 15 & 0 & 35 \\
\hline$>4.0$ & 1 & 2 & 3 & 70 & 0 & 76 \\
\hline Total & 103 & 6 & 8 & 88 & 3 & 211 \\
\hline
\end{tabular}

$\mathrm{CISH}$, chromogenic in situ hybridisation; FISH, fluorescence in situ hybridisation; HER2, human epidermal growth factor receptor 2.

One hundred of the 211 cases evaluated had previously been shown to have a HER2/CEP17 ratio of $<2.0$ as determined by $\mathrm{FISH}$, and were HER2 negative. Of these cases, 94 (94\%) had $\leq 5$ copies of the HER2 gene (no amplification) by $\mathrm{CISH}$. Only three of the $100 \mathrm{FISH}$-negative cases were scored as positive for HER2 gene amplification by $\mathrm{CISH}$. In three cases, no signal could be obtained by $\mathrm{CISH}$.

Thirty-five of the 211 cases included in the study were considered low-amplified cases (FISH HER2/CEP17 ratio between 2.0-4.0); of these, 20 cases had an amplified HER2 gene copy number by $\mathrm{CISH}$, with five containing 6 HER2 gene copies and 15 having $>6$ copies. In 15 of the 30 cases, $\mathrm{CISH}$ did not detect HER2 gene amplification and of these, 11 were found to have a HER2 copy number $<5$ and four had a copy number of 5 .

\section{Inter-laboratory concordance of CISH results}

Table 2 shows the correlation between $\mathrm{CISH}$ performed in the sending laboratory (own $\mathrm{CISH}$ ) and $\mathrm{CISH}$ performed at the receiving laboratory (outside $\mathrm{CISH}$ ).
Ninety-two cases had a high level of amplification ( $>6$ copies per cell) by own $\mathrm{CISH}, 85$ (92\%) demonstrated some degree of HER2 gene amplification ( $\geq 6$ copies per cell) by outside $\mathrm{CISH}$. Seventy-eight of these cases had $>6$ HER2 copies per cell and seven had 6 copies per cell as determined by outside $\mathrm{CISH}$. Seven cases (8\%) were classified as negative for amplification ( $\leq 5$ copies per cell) by outside $\mathrm{CISH}$. Four of these cases had $<5$ HER2 copies per cell and three had 5 copies.

Of the 101 cases that had at least a low-level of HER2 gene amplification ( $\geq 6$ copies per cell) by own $\mathrm{CISH}, 88$ cases also scored positive for amplification by outside $\mathrm{CISH}$ (87\%), six cases scored 5 copies per cell by outside $\mathrm{CISH}$, and seven cases scored $<5$ signals per cell.

Most cases (96 of 101 cases; 95\%) that scored $<5$ copies per cell by own $\mathrm{CISH}$, had no amplification ( $\leq 5$ copies per cell) by outside $\mathrm{CISH}$. Ninety-four of these cases scored $<5$ HER2 copies per cell and two had 5 copies per cell. One case scored 6 HER2 copies per cell as determined by 'outside $\mathrm{CISH}$ ', and three were scored as having $>6$ copies per cell. 
Table 2

\begin{tabular}{|c|c|c|c|c|c|c|}
\hline \multirow[b]{2}{*}{ Own CISH (number of signals) } & \multicolumn{5}{|c|}{ Outside $\mathrm{CISH}$ (number of signals) } & \multirow[b]{2}{*}{$n$} \\
\hline & $<5$ & 5 & 6 & $>6$ & No signal & \\
\hline$<5$ & 94 & 2 & 1 & 3 & 1 & 101 \\
\hline 5 & 0 & 1 & 0 & 2 & 1 & 4 \\
\hline 6 & 3 & 3 & 0 & 3 & 0 & 9 \\
\hline$>6$ & 4 & 3 & 7 & 78 & 0 & 92 \\
\hline No signal & 0 & 0 & 0 & 1 & 1 & 2 \\
\hline Total & 101 & 9 & 6 & 87 & 3 & 208 \\
\hline
\end{tabular}

$\mathrm{CISH}$, chromogenic in situ hybridisation.

Out of the 105 cases scored as negative for HER2 gene amplification ( $\leq 5$ copies per cell) by own $\mathrm{CISH}, 97$ also scored as negative by outside $\mathrm{CISH}$ (92\%). One case had 6 HER2 copies per cell as determined by outside $\mathrm{CISH}$, and five cases had $>6$ copies. No signal was detected in a further two cases.

\section{Intra-laboratory correlation between IHC and CISH}

The correlation between $\mathrm{IHC}$ and $\mathrm{CISH}$ performed in the same laboratory is shown in Table 3. Of the 211 cases included in this study, 86 were scored as HER2 3+ by IHC. Of these, 78 (91\%) were scored as having HER2 gene amplification by $\mathrm{CISH}$ ( $\geq 6$ copies per cell). Of the 50 cases scored as HER2 0 or $1+, 46$ (92\%) showed normal HER2 copy number by $\mathrm{CISH}$. Of the 75 cases scored as HER2 2+ by IHC, 20 (27\%) cases showed HER2 gene amplification as assayed by $\mathrm{CISH}$.

\section{Intra-laboratory correlation between FISH and own CISH} in IHC 2+ cases

According to the current HER2 testing algorithm, $\mathrm{FISH}$ is used to confirm IHC $2+$ cases. All seven IHC $2+$ cases scored as having high levels of amplification by FISH were also scored as highly amplified ( $>6$ copies) by $\mathrm{CISH}(100 \%)$ (Table 4$)$. Of the $47 \mathrm{IHC} 2+$ cases scored as not amplified by $\mathrm{FISH}, 44$ (94\%) were negative by $\mathrm{CISH}(\leq 5)$. Of $18 \mathrm{IHC} 2+$ cases with low amplification by $\mathrm{FISH}, 12$ were negative by $\mathrm{CISH}$ (11 had $<5$ HER2 copies per cell, one had 5 copies per cell), two had 6 copies per cell, and four were scored as having $>6$ copies per cell.

\section{Other quality parameters of the CISH test}

Good CISH staining was seen for $75-100 \%$ of cells in $65 \%$ of the cases examined, $50-75 \%$ of cells in 17\% of cases, $25-$ $50 \%$ of cells in $11 \%$ of the cases and $0-25 \%$ of cells in $7 \%$ of cases.

Tumour cell morphology was found to be excellent in $15.5 \%$ of cases, good in $67 \%$ of cases, and reasonable in $15 \%$ of cases (Table 5). Poor tumour cell morphology was observed in only $2.5 \%$ of cases.

Table 3

Intra-laboratory correlation between CISH and IHC

\begin{tabular}{|c|c|c|c|c|}
\hline \multirow[b]{2}{*}{ Own CISH (number of signals) } & \multicolumn{3}{|c|}{$\mathrm{IHC}$} & \multirow[b]{2}{*}{$n$} \\
\hline & $0 / 1+$ & $2+$ & $3+$ & \\
\hline$<5$ & 44 & 44 & 6 & 104 \\
\hline 5 & 2 & 1 & 1 & 4 \\
\hline 6 & 1 & 5 & 3 & 9 \\
\hline$>6$ & 2 & 15 & 75 & 92 \\
\hline No signal & 1 & 0 & 1 & 2 \\
\hline Total & 50 & 75 & 86 & 211 \\
\hline
\end{tabular}

$\mathrm{CISH}$, chromogenic in situ hybridisation; $\mathrm{IHC}$, immunohistochemistry. 
Table 4

Correlation between FISH and own CISH in IHC 2+ samples

\begin{tabular}{lccccc}
\hline & \multicolumn{2}{c}{ Own CISH (number of signals) } & \\
\cline { 2 - 6 } FISH & $<5$ & 5 & 6 & 0 & $n$ \\
\hline$<2.0$ & 44 & 0 & 3 & 4 & 47 \\
$2.0-4.0$ & 11 & 1 & 2 & 7 & 7 \\
$>4.0$ & 0 & 0 & 0 & 11 & 73 \\
\hline
\end{tabular}

$\mathrm{CISH}$, chromogenic in situ hybridisation; FISH, fluorescence in situ hybridisation; IHC, immunohistochemistry.

Table 5

\begin{tabular}{lcc} 
Tumour cell morphology & Morphology \\
\hline & \multicolumn{2}{c}{$15.5 \%$} \\
Excellent & $33 / 214$ & $67.0 \%$ \\
Good & $144 / 214$ & $15.0 \%$ \\
Reasonable & $32 / 214$ & $2.5 \%$
\end{tabular}

\section{Discussion}

Accurate assessment of HER2 status is essential for identifying patients who are candidates for therapy with the antiHER2 monoclonal antibody trastuzumab. A rapid and accurate test for HER2 status is needed because an increased number of treatment decisions are based on the HER2 status of a patient's disease. In particular, increasing evidence suggests that response to certain forms of hormone treatment and chemotherapy are dependent on a patient's HER2 status [914]. The results of our multicentre ring study show that $\mathrm{CISH}$ is a reliable test for the assessment of HER2 gene copy number.

The study demonstrates excellent correlation between FISH and $\mathrm{CISH}$ results, with $92 \%$ of cases scored as having highlevel amplification by FISH also scoring as having high-level amplification by $\mathrm{CISH}$. In addition, 94\% of cases which were shown to have a normal HER2 gene copy number by FISH appeared to lack HER2 gene amplification by $\mathrm{CISH}$. Inter-laboratory concordance with $\mathrm{CISH}$ was similar to that seen between FISH and outside $\mathrm{CISH} ; 94 \%$ for $\leq 5$ HER2 copies per cell and $92 \%$ for $\geq 6$ HER2 copies per cell.

Intra-laboratory correlation of $\mathrm{IHC}$ with $\mathrm{CISH}$ was also good for cases scored as $3+$ and 0 or $1+$ by $\mathrm{IHC}$ ( $91 \%$ and $92 \%$ of cases respectively). Twenty (27\%) of the 75 cases scored as HER2 2+ by IHC showed HER2 gene amplification as assayed by $\mathrm{CISH}$. This is in agreement with the findings of other studies comparing HER2 overexpression with the degree of HER2 gene amplification. In these studies, the percentage of tumours with a HER2 IHC 2+ score and gene amplification was approximately $25 \%[12,25,26]$.

Accurate scoring of cases with low-level HER2 gene amplification is technically challenging. Therefore, a high number of cases with a HER2/CEP17 ratio of 2.0-4.0 were specifically included for evaluation in this study. According to the FISH scoring guidelines, these cases are positive for HER2 gene amplification. However, 43\% of cases scored as low level of amplification by $\mathrm{FISH}$, but scored as non-amplified by $\mathrm{CISH}$. Further detailed analyses should be conducted in this area to clarify this result. However, it should be noted that breast carcinomas with a low degree of HER2 gene amplification are rare (estimated to be $1-3 \%$ of all carcinomas), and interobserver variability is greatest in this category of samples. Indeed, three out of seven cases with low-level amplification assessed by FISH included in this study gave different results when re-assessed by $\mathrm{FISH}$ in another laboratory (data not shown). A recent inter-observer study for FISH showed that, although agreement was excellent for tumours with normal HER2 gene copy numbers or HER2 gene amplification, there was marked inter-observer variability in these 'borderline cases' [27]. Recently, a consensus panel has proposed adapted scoring guidelines for HER2 testing. An important recommendation from this panel was to consider reporting breast cancer cases with a HER2/centromer chromosome 17 ratio between 1.8 and 2.2 as borderline [28]. Using this adapted scoring guideline, a tumour is assessed as HER2 
amplified when the ratio is more than 2.2 ; or when the absolute number of HER2 gene copies is more than six.

The key to understanding FISH/CISH discrepancy in cases with low-level amplification lies in the nature of the two tests. A significant difference between $\mathrm{FISH}$ and $\mathrm{CISH}$ is that in the most commonly used FISH assay, 2-colour $\mathrm{FISH}$, the copy number of the HER2 gene and of the centromere of chromosome 17 (CEP17) are assessed simultaneously. The signal from the centromere probe functions as an internal control; the final FISH score is based on a ratio of the signals from the two probes. Conversely, in the $\mathrm{CISH}$ assay, the copy number of $H E R 2$ is assessed directly. When classifying tumours with one to four copies, or with $>10$ copies of HER2 by $\mathrm{CISH}$, the HER2 status of the sample is clear. However, in cases with HER2 copy numbers in the range of $4-10$, the HER2/CEP17 ratio may be of importance. Some discrepancies between FISH and $\mathrm{CISH}$ may also be explained for polysomic cases where the FISH assay might indicate a negative testing result, as the HER2/CEP17 ratio is calculated, while $\mathrm{CISH}$ indicates a HER2-positive testing result as the numbers of HER2 signals are assessed. In general, we have also noted that the inter-observer variability in scoring cases with mid-range HER2 copy numbers is relatively large, and also that interobserver variability in scoring HER2/CEP17 ratio with FISH is considerable (unpublished results). According to the Invitrogen scoring system for $\mathrm{CISH}$, supplied by the manufacturer at the start of this study, a score of $\leq 5$ HER2 copies per cell indicates no amplification, whereas a score of $\geq 6$ HER2 copies indicates amplification. This meant that classification of cases with an average CISH score of 5-6 was unclear. However, since this study, Invitrogen has updated its scoring system to specify that a score of $>5$ signals per cell should now be considered indicative of HER2 gene amplification. As we wished to be able to categorize the subgroups in this borderline category more precisely, scoring 5 copies and 6 copies as separate categories was part of the study design. We believe that obtaining a reliable $\mathrm{CISH}$ result for these borderline cases is no more problematic than obtaining a reproduced FISH result for such cases. A practical approach to this problem is to count at least 60 nuclei when the number of HER2 copies ranges from 4-10, and to consider adding $\mathrm{CISH}$ using a CEP17 probe on a consecutive slide to confirm the result. Alternatively, and where possible, dual-colour FISH with probes for HER2 and CEP17 can be considered. It is to be hoped that it will be possible to analyze the studies showing benefit of trastuzumab therapy in the adjuvant setting for the benefit of the subgroup of HER2 low-level/borderline amplified tumours. This may help to better define the analytical approach to this category of tumours.

When own $\mathrm{CISH}$ was compared with FISH in determining the HER2 status of IHC 2+ cases, there was 100\% concordance for HER2-positive samples and 94\% for HER2-negative samples. The good intra-laboratory correlation of $\mathrm{FISH}$ with $\mathrm{CISH}$ suggests that $\mathrm{CISH}$ could potentially be used in place of $\mathrm{FISH}$ to determine the HER2 status of equivocal cases by IHC. As both tests produce similar results in the retesting of equivocal $\mathrm{IHC}$ cases, $\mathrm{CISH}$ could potentially fulfil the same role as $\mathrm{FISH}$ in the HER2 testing algorithm.

$\mathrm{CISH}$ displayed high inter-laboratory concordance, showing that results are reproduced between laboratories. Correlation between own $\mathrm{CISH}$ and outside $\mathrm{CISH}$ was similar to that observed between FISH and outside $\mathrm{CISH}$ with 95\% concordance for cases with $<5$ HER2 copies per cell and $92 \%$ for cases with $>6$ HER2 copies per cell. The most notable discrepancies with $\mathrm{CISH}$ in a few cases are probably the result of technical problems with the staining procedure or with the interpretation of the results. This highlights the need for training before any technology is used for the first time. However, the excellent inter-laboratory correlation of $\mathrm{CISH}$ results highlights its potential as a method for testing HER2-status, even in those laboratories unfamiliar with using $\mathrm{CISH}$.

As can be seen from our results, this study includes cases with a HER2 IHC3+ score but without HER2 gene amplification (as detected by $\mathrm{CISH}$ ); and cases with a HER2 IHCO/1+ score and with HER2 gene amplification (as detected by $\mathrm{CISH})$. The number of discrepancies was very similar if FISH was used instead of $\mathrm{CISH}$ (data not shown). In view of the clinical consequences of accurate HER2 status assessment for many patients, it should be considered to test $\mathrm{CISH}$ (or FISH) alongside IHC either as a diagnostic routine or as part of a quality assurance program in each lab.

The pre-treatment of tissue sections, especially the pepsin digestion time, was a critical step in achieving a good $\mathrm{CISH}$ result. Like $\mathrm{FISH}$, the optimal pepsin digestion time differs between tumours. For practical reasons, the pepsin digestion time used in the preparation of received slides was calculated in each laboratory on the basis of a pepsin time course performed on one representative tumour provided by the sending laboratory. However, it is possible that this was not the optimal value for all tumour samples, and as a result it was likely that in some cases no HER2 signal would be detected. For such cases, it was determined that the CISH test should be repeated after adjustment of the pepsin digestion time. Using this strategy, a good result was obtained in $99 \%$ of the cases (208 out of 211). In all cases, the percentage of tumour cells for which HER2 copy number could be assessed by $\mathrm{CISH}$ was recorded; this percentage was $>50 \%$ for most cases (data not shown). There were no cases in this series where noticeable heterogeneity in the number of HER2 signals per tumour cell was observed.

An advantage of $\mathrm{CISH}$ over $\mathrm{FISH}$ is that invasive tumour cells can be easily identified using a light microscope, provided that the morphology of the tissue is good following $\mathrm{CISH}$ staining. More than $80 \%$ of the tumours examined to date in this study 
Figure 3

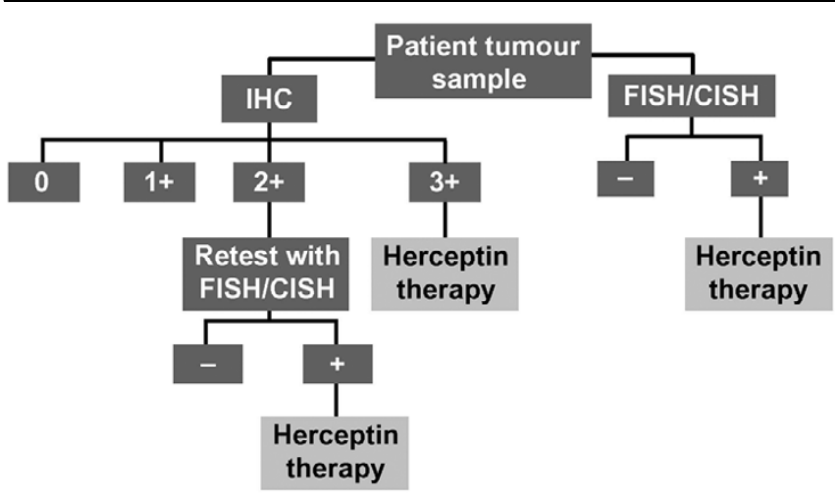

The recommended HER2 testing algorithm. Reprinted with permission from W Hanna.

had either good or excellent morphology, illustrating this beneficial aspect of $\mathrm{CISH}$ testing.

\section{Conclusion}

This validation ring study demonstrates that $\mathrm{CISH}$ is a very powerful test for the determination of HER2 gene copy numbers in breast cancer specimens. Moreover, $\mathrm{CISH}$ also has significant advantages over FISH, which is considered to be the reference standard for determination of HER2 gene amplification. These results are similar to the findings of other studies that have evaluated $\mathrm{CISH}$ [19-24]. The concordance of $\mathrm{CISH}$ with FISH in this study is especially encouraging as $\mathrm{CISH}$ tests were performed in a different laboratory to the one in which the tumour sections were prepared, which adds a greater level of significance to these trial results. Therefore, in view of these results, we suggest that $\mathrm{CISH}$ can be used as an alternative method to FISH in the current HER2 testing algorithm (Figure 3).

\section{Competing interests}

MvdV, MB, WH, F P-L and JR are members of the F HoffmannLa Roche AG Herceptin Pathology Advisory Board and are payed honoraria for attendance at these meetings. $\mathrm{MH}$ declares that he has received honoraria from $F$ Hoffmann-La Roche AG for teaching about the assessment of HER2 on several occasions in recent years. PK declares that she has no competing interests.

\section{Authors' contributions}

Each of the authors was involved in the design of the study; in overseeing the staining of the slides; and in interpreting the staining results. MvdV and PK were involved in analyzing the data. All the authors were involved in drafting the manuscript.

\section{Acknowledgements}

The authors wish to thank Claire Snowball for editorial support with this manuscript.

The study was supported by an unrestricted educational grant from $\mathrm{F}$ Hoffmann-La Roche AG.

\section{References}

1. Akiyama $\mathrm{T}$, Sudo $\mathrm{C}$, Ogawara $\mathrm{H}$, Toyoshima $\mathrm{K}$, Yamamoto $\mathrm{T}$ : The product of the c-erbB-2 gene: a 185-kilodalton glycoprotein with tyrosine kinase activity. Science 1986, 232:1644-1646.

2. Hynes NE, Stern DF: The biology of erbB-2/neu/HER-2 and its role in cancer. Biochim Biophys Acta 1994, 1198:165-184.

3. Nagai MA, Pacheco MM, Oshima CT, Brentani MM: c-erbB-2 DNA amplification and mRNA expression in human primary breast tumors and its relationship to other prognostic factors. Cancer Biother 1993, 8:29-35.

4. Pauletti G, Godolphin W, Press MF, Slamon DJ: Detection and quantitation of HER-2/neu gene amplification in human breast cancer archival material using fluorescence in situ hybridization. Oncogene 1996, 13:63-72.

5. Hoang MP, Sahin AA, Ordonez NG, Sneige N: HER-2/neu gene amplification compared with HER-2/neu protein overexpression and interobserver reproducibility in invasive breast carcinoma. Am J Clin Pathol 2000, 113:852-859.

6. Tubbs RR, Pettay J, Roche P, Stoler MH, Jenkins R, Myles J, Grogan T: Concomitant oncoprotein detection with fluorescence in situ hybridization (CODFISH). A fluorescence-based assay enabling simultaneous visualization of gene amplification and encoded protein expression. J Mol Diagn 2000, 2:78-83.

7. Vaziri SAJ, Tubbs RR, Darlington G, Casey G: Absence of CCND1 gene amplification in breast tumours of BRCA1 mutation carriers. Mol Pathol 2001, 54:259-263.

8. Slamon DJ, Godolphin W, Jones LA, Holt JA, Wong SG, Keith DE, Levin WJ, Stuart SG, Udove J, Ullrich A, et al:: Studies of the HER-2/neu proto-oncogene in human breast and ovarian cancer. Science 1989, 244:707-712.

9. Budman DR, Berry DA, Cirrincione CT, Henderson IC, Wood WC Weiss RB, Ferree CR, Muss HB, Green MR, Norton L, et al:: Dose and dose intensity as determinants of outcome in the adjuvant treatment of breast cancer. The Cancer and Leukemia Group B. J Natl Cancer Inst 1998, 90:1205-1211.

10. De Laurentiis M, Arpino G, Massarelli E, Ruggiero A, Carlomagno C, Tortora G, Ciardiello F, Bianco AR, De Placido S: HER2 as predictive marker of resistance to endocrine treatment (ET) for advanced breast cancer (ABC): a metanalysis of published studies [abstract]. Breast Cancer Res Treat 2002, 76(Suppl 1):S68. poster update

11. Hanna W: Testing for HER2 status. Oncology 2001, 61(Suppl 2):22-30

12. Lebeau $A$, Deimling $D$, Kaltz $C$, Sendelhofert $A$, Iff $A$, Luthardt $B$, Untch M, Lohrs U: Her-2/neu analysis in archival tissue samples of human breast cancer: comparison of immunohistochemistry and fluorescence in situ hybridization. J Clin Oncol 2001, 19:354-363.

13. Leitzel K, Teramoto $\mathrm{Y}$, Konrad K, Chinchilli VM, Volas G, Grossberg $\mathrm{H}$, Harvey H, Demers L, Lipton A: Elevated serum c-erbB-2 antigen levels and decreased response to hormone therapy of breast cancer. J Clin Oncol 1995, 13:1129-1135.

14. Piccart M, Lohrisch C, Di Leo A, Larsimont D: The predictive value of HER2 in breast cancer. Oncology 2001, 61(Suppl 2):73-82.

15. Slamon DJ, Leyland-Jones B, Shak S, Fuchs H, Paton V, Bajamonde A, Fleming T, Eiermann W, Wolter J, Pegram M, Baselga J, Norton L: Use of chemotherapy plus a monoclonal antibody against HER2 for metastatic breast cancer that overexpresses HER2. N Engl J Med 2001, 344:783-792.

16. Marty M, Cognetti F, Maraninchi D, Snyder R, Mauriac L, TubianaHulin M, Chan S, Grimes D, Antón A, Lluch A, et al.: Efficacy and safety of trastuzumab combined with docetaxel in patients with HER2-positive metastatic breast cancer given as first-line treatment: results of a randomized phase II trial (M77001). J Clin Oncol 2005, 23:4265-4274.

17. Baselga J: Herceptin alone or in combination with chemotherapy in the treatment of HER2-positive metastatic breast cancer: pivotal trials. Oncology 2001, 61:14-21.

18. Bilous $M$, Dowsett $M$, Hanna $W$, Isola J, Lebeau A, Moreno A, Penault-Llorca F, Ruschoff J, Tomasic G, van de Vijver M: Current perspectives on HER2 testing: a review of national testing guidelines. Mod Pathol 2003, 16:173-182.

19. Isola J, Tanner M, Forsyth A, Cooke TG, Watters AD, Bartlett JM: Interlaboratory comparison of HER-2 oncogene amplification 
as detected by chromogenic and fluorescence in situ hybridization. Clin Cancer Res 2004, 10:4793-8.

20. Tanner M, Gancberg D, Di Leo A, Larsimont D, Rouas G, Piccart $\mathrm{MJ}$, Isola J: Chromogenic in situ hybridisation: a practical alternative for fluorescence in situ hybridisation to detect HER-2/ neu oncogene amplification in archival breast cancer samples. Am J Pathol 2000, 157:1467-1472.

21. Zhao J, Wu R, Au A, Marquez A, Yu Y, Shi Z: Determination of HER2 gene amplification by chromogenic in situ hybridization (CISH) in archival breast carcinoma. Mod Pathol 2002, 15:657-665.

22. Dandachi N, Dietze O, Hauser-Kronberger C: Chromogenic in situ hybridisation: a novel approach to a practical and sensitive method for the detection of HER2 oncogene in achival human breast carcinoma. Lab Invest 2002, 82:1007-1014.

23. Arnould L, Denoux $Y$, MacGrogan G, Penault-Llorca F, Fiche M, Treilleux I, Mathieu MC, Vincent-Salomon A, Vilain MO, Couturier $\mathrm{J}$ : Agreement between chromogenic in situ hybridisation (CISH) and FISH in the determination of HER2 status in breast cancer. Br J Cancer 2003, 88:1587-1591.

24. Tubbs R, Pettay J, Skacel M, Hicks D, Mele J, Powell R, Chen T, Nita $\mathrm{H}$, Grogan T, Hainfeld J: Automated chromogenic in situ hybridization (CISH) for detection of HER2 gene amplification. USACAP (poster 17). March 25, 2003

25. Mass R, Sanders C, Kasian C, Johnson L, Everett T, Anderson S: The concordance between the clinical trials assay (CTA) and fluorescence in situ hybridization (FISH) in the Herceptin pivotal trials. Proc Am Soc Clin Oncol 2000, 19:75a.

26. Tsuda $H$, Akiyama $F$, Terasaki $H$, Hasegawa $T$, Kurosumi M, Shimadzu M, Yamamori S, Sakamoto G: Detection of HER-2/neu (cerb B-2) DNA amplification in primary breast carcinoma. Interobserver reproducibility and correlation with immunohistochemical HER-2 overexpression. Cancer 2001, 92:2965-2974.

27. Isola J, Tanner M, Forsyth A, Cooke TG, Watters AD, Bartlett JM: Interlaboratory comparison of HER-2 oncogene amplification as detected by chromogenic and fluorescence in situ hybridization. Clin Cancer Res 2004, 10:4793-8.

28. Dowsett M, Hanna WM, Kockx M, Penault-Llorca F, Ruschoff J, Gutjahr T, Habben K, van de Vijver MJ: Standardization of HER2 testing: results of an international proficiency-testing ring study. Mod Pathol 2007, 20:584-91. 